OPEN ACCESS

Edited by:

Hans Keune,

Belgian Biodiversity Platform, Belgium

Reviewed by:

Unnikrishnan Payyappallimana,

Transdisciplinary University, India

Bruno Marchal,

Institute of Tropical Medicine

Antwerp, Belgium

${ }^{*}$ Correspondence:

Nicole Redvers

nicole.redvers@und.edu

Specialty section:

This article was submitted to

Planetary Health,

a section of the journal

Frontiers in Public Health

Received: 09 March 2021

Accepted: 08 April 2021

Published: 30 April 2021

Citation:

Redvers N (2021) Patient-Planetary

Health Co-benefit Prescribing:

Emerging Considerations for Health

Policy and Health Professional

Practice.

Front. Public Health 9:678545. doi: 10.3389/fpubh.2021.678545

\section{Patient-Planetary Health Co-benefit Prescribing: Emerging Considerations for Health Policy and Health Professional Practice}

\author{
Nicole Redvers ${ }^{1,2 *}$ \\ ${ }^{1}$ Department of Family \& Community Medicine, University of North Dakota School of Medicine \& Health Sciences, Grand \\ Forks, ND, United States, ${ }^{2}$ Nuffield Department of Primary Care Health Sciences, University of Oxford, Oxford, \\ United Kingdom
}

In addition to the importance of fostering and developing measures for better health-system resilience globally from the effects of climate change, there have been increasing calls for health professionals, as well as public health and medical education systems, to become partners in climate change mitigation efforts. Direct clinical practice considerations, however, have not been adequately fostered equitably across all regions with an often-confusing array of practice areas within planetary health and sustainable healthcare. This article calls for a more coordinated effort within clinical practice spaces given the urgency of global environmental change, while also taking lessons from Indigenous traditional knowledge systems - a viewpoint that is rarely heard from or prioritized in public health or medicine. Simpler and more coordinated messaging in efforts to improve patient and planetary health are needed. The creation of unifying terminology within planetary health-rooted clinical and public health practice has been proposed with the potential to bring forth dialogue between and within disciplinary offshoots and public health advocacy efforts, and within clinical and health-system policy spaces.

Keywords: planetary health, co-benefits, health professionals, climate change, sustainable healthcare, prescribing practices, Indigenous knowledges

\section{INTRODUCTION}

Planetary health is a field focused on characterizing the linkages between human-caused disruptions of Earth's natural systems (e.g., climate change, deforestation, pollution) and the resulting impacts on public health (1). The field of planetary health aims to develop and evaluate evidence-based solutions to safeguard an equitable, sustainable, and healthy world (2). This aim is platformed on a sense of urgency underscored in a recent Intergovernmental Panel on Climate Change (IPCC) special report outlining the need to make drastic cuts in greenhouse gas emissions by 2030 (by about $45 \%$ from 2010 levels) in order to prevent temperature rises exceeding 1.5 degrees Celsius above pre-industrial levels (3). With this, there is a proposed stronger need for climate action in wider spheres of influence, which includes public health-system structures and clinical practice. Ultimately, the contributions toward an action-orientated road map to net zero greenhouse gas emissions within healthcare needs to align with current planetary health and sustainability targets globally. 
If the global healthcare sector were its own country, it would be the 5th largest greenhouse gas emitter on the planet (4). Acknowledging the clear impacts between various interconnected global environmental changes [e.g., global warming, pollution, biodiversity loss (see Table 1 for important definitions)] in the health of humans and other species, the current Director General of the World Health Organization, Tedros Adhanom Ghebreyesus has stated that, "Health sector facilities are the operational heart of service delivery, protecting health, treating patients, and saving lives. Yet health sector facilities are also a source of carbon emissions, contributing to climate change. Places of healing should be leading the way, not contributing to the burden of disease" (4). The Sustainable development goals (SDGs), adopted by all United Nations Member States in 2015, also ensures a spotlight on the need for improving health and reducing inequalities, while also tackling climate change and preserving biodiversity (12). Therefore, there is a clear need to bring together health and sustainable development using strategies that reduce greenhouse gas emissions, pollution, and deforestation (13).

In 2015, the World Health Organization (WHO) published an operational framework for building climate resilient health systems (14). The focus of the report was to enable health systems globally to be better able to anticipate, prevent, prepare for, and manage climate-related health risks (14). Despite the importance of fostering and developing measures to ensure health-system resilience globally from the effects of climate change (i.e., adaptation), there have been increasing calls for health professionals, as well as public health and medical education systems, to become partners in climate change mitigation efforts $(1,15,16)$. Despite this call to action for health-professional involvement in mitigation efforts, there is evidence demonstrating that in some regions clinicians may not actually feel comfortable counseling patients specifically around climate change impacts and health $(64 \%$ percent of primary care physicians in one US state believe climate change was affecting their patients' health, whereas only $17 \%$ were comfortable counseling patients about climate change and health) (17). Direct clinical practice considerations have therefore not been adequately fostered at the health provider or institutional level, with current policy planning efforts for developing meaningful mitigation and adaptation measures often focusing on interactions and impacts outside of the clinical exam room. Although warranted, if health professionals are to be called to action in the fast-evolving climate change crisis, more scholarly, clinical, and policy attention is urgently needed in how to operationalize this call.

To date, there have been a number of actions specifically proposed that clinicians can take in promoting individual and planetary health within their own practices and communities $(1,18)$. These stated planetary health actions stem from climate adaptation measures through the lens of preparedness and responsiveness, to global environmental change mitigation measures through advising patients directly within clinical care on potential co-benefit actions for people and the environment (see Table 2). Additionally, there has been increasing focus on
TABLE 1 | Important terminology used in the field of planetary health.

\begin{tabular}{|c|c|}
\hline Terminology & Definition \\
\hline $\begin{array}{l}\text { Planetary Health } \\
\text { (Western) }\end{array}$ & $\begin{array}{l}\text { A field focused on characterizing the linkages between } \\
\text { human-caused disruptions of Earth's natural systems } \\
\text { and the resulting impacts on public health (1). }\end{array}$ \\
\hline $\begin{array}{l}\text { Planetary Health } \\
\text { (Indigenous) }\end{array}$ & $\begin{array}{l}\text { Planetary health as a "field" is primarily a Western } \\
\text { construct as Indigenous Traditional Knowledge systems } \\
\text { have no clear separation between the health of the } \\
\text { planet and the health of self or that of the community } \\
\text { and the ecosystem at large (5). This means that the } \\
\text { meaning and applications of planetary health are directly } \\
\text { rooted in community values based on protocols for living } \\
\text { in harmony with all that have existed for thousands of } \\
\text { years (6). }\end{array}$ \\
\hline Climate Change & $\begin{array}{l}\text { A change in climate that is attributed directly or indirectly } \\
\text { to human activity that alters the composition of the } \\
\text { global atmosphere and that, in addition to natural climate } \\
\text { variability, is observed over comparable time periods (7). }\end{array}$ \\
\hline Global Warming & $\begin{array}{l}\text { The long-term heating of Earth's climate system } \\
\text { observed since the pre-industrial period due to human } \\
\text { activities, primarily fossil fuel burning, which increases } \\
\text { heat-trapping greenhouse gas levels in Earth's } \\
\text { atmosphere (8). }\end{array}$ \\
\hline $\begin{array}{l}\text { Global Environmental } \\
\text { Change (GEC) }\end{array}$ & $\begin{array}{l}\text { Large-scale and global environmental changes include } \\
\text { climate change, stratospheric ozone depletion, changes } \\
\text { in ecosystems due to loss of biodiversity, changes in } \\
\text { hydrological systems and the supplies of freshwater, land } \\
\text { degradation, urbanization, and stresses on } \\
\text { food-producing systems (9). }\end{array}$ \\
\hline Biodiversity Loss & $\begin{array}{l}\text { The decrease in the variety of life on Earth in all its forms } \\
\text { (i.e., the diversity within species, between species and of } \\
\text { ecosystems) (10). One million species out of an } \\
\text { estimated total of eight million species are threatened } \\
\text { with extinction, many within decades (10). }\end{array}$ \\
\hline Co-benefits & $\begin{array}{l}\text { The potentially large and diverse range of collateral } \\
\text { benefits that can be associated with climate change } \\
\text { mitigation policies in addition to the benefits derived from } \\
\text { directly avoiding climate impacts (11). }\end{array}$ \\
\hline
\end{tabular}

the "Why? What? And How? of educating for environmentally sustainable healthcare education" $(29,30)$, as well as the push to re-define quality improvement (QI) in healthcare to include environmental sustainability $(31,32)$. Even specialtyspecific environmental sustainability best practices are ongoing $(33,34)$, with regional organizations such as the Center for Sustainable Healthcare leading the way in offering strategic input, consultancy, and training in sustainable healthcare practice within the UK specifically as well as abroad (35). There are also continually evolving academic and practice movements within environmental public health, One Health, EcoHealth, and of course Planetary Health. Each approach to tackling the urgency of climate change and biodiversity loss has its strengths and opportunities; however, for clinicians, the multitude of terminologies and areas of discourse do not always translate down to the clinical exam room. With this, there is an important need for synergy among any proposed clinical approaches that seek to provide benefit to both the patient and the planet. 
TABLE 2 | Summary of some of the existing patient-planetary co-benefit actions that have been proposed [partially adapted from WONCA Working Party on the Environment (1)].

\begin{tabular}{|c|c|}
\hline Co-benefits & Description \\
\hline Food choices & $\begin{array}{l}\text { A transition to a more sustainable plant-based diet-rich } \\
\text { in fruits, vegetables, nuts, and legumes - can reduce the } \\
\text { environmental footprint of agriculture, as recently } \\
\text { highlighted by the EAT-Lancet Commission }(19,20) \text {. }\end{array}$ \\
\hline Active transport & $\begin{array}{l}\text { Forms of transport that involve physical activity, such as } \\
\text { cycling and walking, have the dual benefit of reducing } \\
\text { emissions and protecting against multiple diseases (13). }\end{array}$ \\
\hline Reproductive health & $\begin{array}{l}\text { Ensuring universal access to reproductive healthcare can } \\
\text { improve both maternal and child health and limit } \\
\text { population growth by reducing unwanted pregnancies } \\
\text { (21). }\end{array}$ \\
\hline $\begin{array}{l}\text { Connecting within } \\
\text { nature }\end{array}$ & $\begin{array}{l}\text { Finding ways to spend more time outside in } \\
\text { nature-including in green space in cities - can have } \\
\text { benefits for physical and mental health }(22) \text { and increase } \\
\text { a sense of stewardship for our natural environment } \\
(23,24) \text {. }\end{array}$ \\
\hline $\begin{array}{l}\text { Engaging in } \\
\text { community }\end{array}$ & $\begin{array}{l}\text { Fostering social connectedness through community } \\
\text { building not only results in mental-health benefits, but } \\
\text { can also help build the social capital necessary for } \\
\text { collective action (25). Connecting with those around us is } \\
\text { thought to be particularly effective for planetary health } \\
\text { when mobilizing around a common goal, such as } \\
\text { bringing more green space, bike lanes, composting } \\
\text { services, or farmers' markets to our communities (1) }\end{array}$ \\
\hline $\begin{array}{l}\text { Sustainable drug } \\
\text { prescribing }\end{array}$ & $\begin{array}{l}\text { Eco-directed Sustainable Drug Prescribing (EDSP) has } \\
\text { been proposed to prevent the adverse effects of some } \\
\text { active pharmaceutical ingredients (APIs) in the } \\
\text { environment (26). Other medications have been } \\
\text { highlighted for their global warming potential (GWP) with } \\
\text { statements being issued to inform clinicians on potential } \\
\text { alternatives (27). }\end{array}$ \\
\hline $\begin{array}{l}\text { Preventative } \\
\text { medicine }\end{array}$ & $\begin{array}{l}\text { With an increase in the overall global population as well } \\
\text { as the aged, the carbon footprint of healthcare is not } \\
\text { improving, and the complexity of diagnostic and } \\
\text { treatment methods used is increasing (28). Disease } \\
\text { prevention strategies are important for patients as well as } \\
\text { for reducing the intensity of the high carbon care } \\
\text { required (28). }\end{array}$ \\
\hline
\end{tabular}

\section{Patient-Planetary Health Co-benefit Prescribing}

The term "co-benefits" has increasingly been used in climate change and planetary health discourse. Instead of considering climate change specifically in isolation for example, a co-benefit approach considers how climate change mitigation initiatives can also advance other policy goals (36), while also leading to improvements in health (37). This fits in with the aims of planetary health, which is to develop and evaluate evidence-based solutions to safeguard an equitable, sustainable, and healthy world (2). Operationalized clinically, a co-benefit approach would seek to consider both the individual's and the planet's health in the context of the medical advice given (1). What is not explicit in the co-benefit framing however is the often nuanced uneven prioritization of people over planet in policy and implementation. In considering a new framework for defining co-benefits, while taking into consideration the multiple evolving

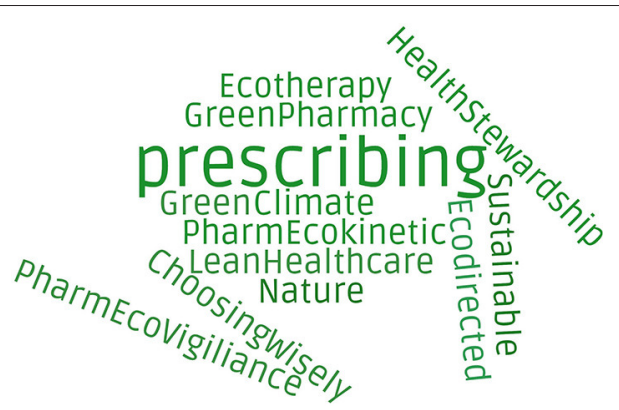

FIGURE 1 | Some examples of the multiple and often independently evolving prescribing terminologies and practice areas that seek to improve the health of people and planet.

terminologies and practice areas that seek to improve the health of people and planet (see Figure 1), a synergistic and interconnected perspective is needed that highlights healthy patients and a healthy planet without hierarchy, terminology dissonance, and overall confusion. Lessons can be gleaned in this regard from Indigenous knowledge systems as presented below.

Indigenous languages worldwide, for example, are completely and utterly based and rooted within relationships to the land (38). The process of putting words and terminologies together is not without careful thought to their relationships with each other, and the symbolisms, interpretations, and actions that could come from their use. This is exemplified by the tight connection between language and Indigenous knowledges as it relates to biodiversity (39). In considering this, how we use language can be a powerful tool for both awareness and implementation processes within and outside of healthcare (40).

In the current efforts to create climate-friendly clinical prescriptions, or clinical consults with climate change in mind, we are automatically framing our work through the lens of an issue or a problem to be solved outside of ourselves (i.e., climate change). This is in direct opposition to the Indigenous worldview in which everything is entirely interconnected (41), and demonstrated additionally by the Indigenous conceptualization of planetary health seen in Table $\mathbf{1}$. With environmentally sustainable clinical practices developing in response to a "state" (i.e., the climate crisis), as opposed to the focused recognition of the need for "ongoing" interconnected relationship building between patient and planet (i.e., ongoing stewardship vs. a situation-based action), we mechanize our process of clinical delivery against a deficit state. Patientplanetary health considerations and therefore discourse should be framed in perpetuity from a strengths-based perspective regardless of the state of the world's environment and climate. Climate change or not, it is important to understand that environmental values are human values, that our planet is a responsive relative, and that public health and healthcare stewardship can only be truly effective through an interconnected worldview that prioritizes ongoing relationships instead of reactive elements and current states. Health professionals have a moral responsibility to deeply consider their "professional role to promote public health and address threats to psychological 
and physical welfare" with the climate and biodiversity-loss crisis lying "within the moral remit of medicine" (42); however, this should not be bounded by crisis alone.

The joining of "patient-planetary health" therefore is purposeful in that the grammatical hyphen itself is connecting the two words together, subtly elucidating their direct interconnection. The joining of the terms also seeks to remove any hierarchical inclination of one focus over the other, instead ensuring the view is always on both elements equitably in considering a co-benefit perspective. "Patient-planetary health co-benefit prescribing" would therefore be overarching terminology to denote any and all prescribing practices that have co-benefits for both patient and planetary health. Patientplanetary health co-benefit prescribing may therefore provide a potential umbrella lens for how we might consider co-benefit practices within public health and healthcare spaces, with room to allow flexibility under the heading itself. Putting heuristics aside, the creation of unifying terminology within planetary health-rooted clinical and public health practice spaces has the potential to bring forth dialogue between and within disciplinary offshoots and advocacy efforts, and within public health and health system policy spaces. Consistency in language, coordinated efforts and messaging across public health, health systems, and policy spaces have been exemplified within other areas of prescribing practice, including the area of antimicrobial stewardship, which required mobilizing transdisciplinary behavioral approaches across multiple regions (43). Lessons can be learned from other complex efforts to improve patient and planetary health.

With a growing multitude of international efforts, we need clearer messaging for our care providers and health-system leaders alongside our push for planetary health aware, climateresponsive health systems. Patient-planetary health co-benefit prescribing practices (e.g., sustainable drug prescribing, nature prescribing, planetary friendly diets, etc.), may offer one way to drive change from within clinical care systems with the path made clearer by unifying the confusing array of sustainabilitypractice terminologies under one umbrella heading and a field of practice (i.e., planetary health). Patient-planetary health cobenefit prescribing may also itself fall under greater planetary healthcare frameworks (28), or sustainable quality improvement processes $(31,32)$ that also encompass sustainability and stewardship needs outside of the patient care room.

An overarching systems approach to implementing planetary healthcare frameworks within public health and healthcare is also needed $(28,44)$. Success may be more likely by specifically focusing on leveraging existing relationships between organizations (planetary health, EcoHealth, One Health, environmental public health, etc.), and clinical practice approaches (green prescribing, climate prescribing, etc.) for greater overall dissipation and impact (i.e., planetary health aware, climate-responsive health systems down to the patient care level). Given the complexity parameters surrounding both health systems and global environmental change, emergent areas of patient-planetary health co-benefit practice points can optimally be further refined, organized, and deliberate in their developing application with patients, institutions, and with health policy planning. Due to the variances in healthsystem delivery, political structures, and payment models globally, specific locally appropriate adaptations and policy considerations will likely be needed under the patient-planetary health co-benefit umbrella. Behavioral systems approaches that take into account individual and policy level drivers (45) may also be applicable and potentially leveraged in the process of further developing clinical and public health practice guidelines given the importance of clinician behavior change in any implementation process $(45,46)$.

Notwithstanding, this proposed effort and dialogue also attempts to break down traditional public health and healthcare silos, including within many current environmental healthcare sustainability spaces, which have historically and contemporarily minimized the voices and knowledge systems of Black, Indigenous, and People of Color (BIPOC) communities. For example, given "the colonial legacy, Indigenous people, despite their essential knowledge systems and abilities, still face many barriers in terms of access to safe spaces and presence, but also in the ability to take on active leadership roles in health professions education," and therefore additionally in education for sustainable healthcare (41). Holistic discourse is needed within planetary health broadly that amplifies lessons learned from Indigenous Peoples' traditional medicine systems and their long-standing sustainable models of health delivery (47).

The training of our Indigenous healers through traditional Indigenous ways of learning is centered around a values-based system that reflects the interconnectedness of all things. These values promote and uplift shared stewardship goals through a set of natural laws derived from the land on which the training takes place. There has so far been a lost opportunity for potential learning from the long histories of Indigenous healing and environmentally sustainable medicine traditions around the world that could inform sustainable healthcare practices. These healing knowledge systems are based on the notion of collective responsibility for health and wellness without hierarchy that includes innate notions of environmental stewardship (41).

Knowledge translation and intercultural dialogue between Western and Indigenous health systems $(48,49)$, as well as evolving scholarship (50,51), expanding integrative health delivery systems (52-54), and discussions around the ethical basis for medical pluralism $(55,56)$ is on the rise. Despite differing worldviews between biomedical clinical settings and Indigenous traditional knowledge settings, we are at a clear interface in time where our ability to sustain ourselves on this planet is in question. Indigenous traditional knowledge is deep, evidenced-informed, resilient, and time tested, yet it does not come without Indigenous Peoples themselves. Established international agreements that serve to protect Indigenous Peoples and their knowledges, and the proactive protection of intellectual property and data sovereignty rights must be front and center to avoid the further perpetuation of inequities and discrimination of Indigenous Peoples (57). Moving forward "in a good way" (58) will require the elevation and amplification of Indigenous voices within healthcare spaces, including within planetary health and sustainability spaces (41). 


\section{CONCLUSION}

Simpler and more coordinated messaging in health system efforts to improve patient and planetary health are needed. The creation of unifying terminology within planetary health-rooted clinical and public health practice spaces has been proposed with the potential to bring forth dialogue between and within disciplinary offshoots and public-health advocacy efforts, and within clinical and health-system policy spaces. The critical need and purpose for defining patient-planetary health co-benefit prescribing frameworks will be seen to have been historically rooted in the climate change crisis; however, it will hopefully be predicated on the innate understanding that patients, their communities, and the planet are locked into an interconnected web of relationships that crosses all boundaries of systems, policy, and practice. An exemplified interprofessional planetary health pledge has recently been proposed (59) that embodies the importance of epistemological pluralism and diversity in action, while also recognizing the interconnected entanglement between individual, community, and planetary health. We are ultimately stronger in our cultural and knowledge diversity, including in the ways we practice public health and medicine. Gone are the times when focusing solely on human-centric approaches to health will make us and our communities well. In further considering the current dual climate-biodiversity loss crisis and the pandemic crisis, human-centric approaches to health and well-being was never really an option for us-we have fallen

\section{REFERENCES}

1. WONCA (Working Party on the Environment). Declaration Calling for Family Doctors of the World to Act on Planetary Health. The World Organization of Family Doctors (WONCA). (2019). Available online at: https://www.wonca.net/site/DefaultSite/filesystem/documents/Groups/ Environment/2019\%20Planetary\%20health.pdf (accessed February 4, 2021).

2. Whitmee S, Haines A, Beyrer C, Boltz F, Capon AG, De Souza Dias BF, et al. Safeguarding human health in the anthropocene epoch: report of the rockefeller foundation-Lancet commission on planetary health. Lancet. (2015) 386:1973-2028. doi: 10.1016/S0140-6736(15)60901-1

3. IPCC Special Report: Global Warming of $1.5^{\circ}$ C, 2018. (2018). Available online at: https://www.ipcc.ch/sr15/ (accessed February 4, 2021).

4. Health Care Without Harm. Health Care's Climate Footprint. (2019). Available online at: https://noharm-global.org/documents/health-careclimate-footprint-report (accessed March 31, 2021).

5. United Nations. Convention on Biological Diversity- In Nagoya Protocol on Access and Benefit-Sharing. (2011). Available online at: https://www.cbd.int/ abs/ (accessed March 31, 2021).

6. Redvers N, Poelina A, Schultz C, Kobei DM, Githaiga C, Perdrisat M, et al. Indigenous natural and first law in planetary health. Challenges. (2020) 11:29. doi: 10.3390/challe11020029

7. United Nations. United Nations Framework Convention on Climate Change. (1992). Available online at: https://unfccc.int/resource/docs/convkp/conveng. pdf (accessed March 31, 2021).

8. NASA Global Climate Change. Overview: Weather, Global Warming and Climate Change. (2021). Available online at: https://climate.nasa.gov/ resources/global-warming-vs-climate-change/ (accessed March 31, 2021).

9. WHO. Climate Change and Human Health- Global Environmental Change. (2021). Available online at: https://www.who.int/globalchange/environment/ en/ (accessed March 31, 2021).

10. IPBES. Global Assessment Report on Biodiversity and Ecosystem Services of the Intergovernmental Science-Policy Platform on Biodiversity and Ecosystem too far away from our healing relationship and interdependence within nature. This nature disconnect will only grow unless we consider transformative changes inside and outside public health and healthcare spaces.

“... a key argument put forward by Indigenous knowledge systems is that health, and ill-health, emerges out of both the nature of the environment within which the individual lives and the individual's connection with that environment." (60)

\section{DATA AVAILABILITY STATEMENT}

The original contributions presented in the study are included in the article/supplementary material, further inquiries can be directed to the Corresponding Author.

\section{AUTHOR CONTRIBUTIONS}

The author confirms being the sole contributor of this work and has approved it for publication.

\section{ACKNOWLEDGMENTS}

Thank you to Dr. Sarah Tonkin-Crine, PhD, at the University of Oxford, for her continued support of this work. Mahsi cho (thank you) to my Dene Elders from the Northwest Territories, Canada, that continue to inspire my work in planetary health.

Services. (2019). Available online at: https://www.ipbes.net/global-assessment (accessed March 31, 2021).

11. Bollen J, Guay B, Jamet S, Corfee-Morlot J. Co-Benefits of Climate Change Mitigation Policies. (2009). Available online at: https://www.oecd-ilibrary.org/ docserver/224388684356.pdf? expires=1617328796\&id=id\&accname=guest $\&$ checksum=033F373C1474E9DE7A9715858E0297EC (accessed March 31, 2021).

12. United Nations Department of Economic and Social Affairs. Make the SDGs a Reality 2021. (2021). Available online at: https://sdgs.un.org/ (accessed March 31, 2021).

13. Roundtable on Environmental Health Sciences R, and Medicine; Board on Population Health and Public Health Practice; Institute of Medicine, editor Health Goals and Indicators for Sustainable Development. Global Development Goals and Linkages to Health and Sustainability: Workshop Summary. Washington, DC: National Academies Press (US) (2013).

14. WHO. Operational Framework for Building Climate Resilient Health Systems. (2015). Available online at: https://www.who.int/globalchange/publications/ building-climate-resilient-health-systems/en/ (accessed February 4, 2021).

15. Veidis EM, Myers SS, Almada AA, Golden CD, on behalf of the Clinicians for Planetary Health Working Group. A call for clinicians to act on planetary health. Lancet. (2019) 393:P2021. doi: 10.1016/S0140-6736(19) 30846-3

16. McKimm J, Redvers N, El Omrani O, Parkes MW, Elf M, Woollard R. Education for sustainable healthcare: leadership to get from here to there. Med Teacher. (2020) 42:1123-7. doi: 10.1080/0142159X.2020.1795104

17. Boland TM, Temte JL. Family medicine patient and physician attitudes toward climate change and health in wisconsin. Wilderness Environ Med. (2019) 30:386-93. doi: 10.1016/j.wem.2019.08.005

18. Iacobucci G. Planetary health: wONCA urges family doctors to commit to action. BMJ. (2019) 364:11002. doi: 10.1136/bmj.11002

19. Commission E-L. EAT-Lancet Commission Brief for Healthcare Professionals. (2019). Available online at: https://eatforum.org/lancet-commission/ healthcare-professionals/ (accessed February 4, 2021). 
20. Aleksandrowicz L, Green R, Joy EJ, Smith P, Haines A. The impacts of dietary change on greenhouse gas emissions, land use, water use, and health: a systematic review. PLoS ONE. (2016) 11:e0165797. doi: 10.1371/journal.pone.0165797

21. Osotimehin B. Family planning as a critical component of sustainable global development. Glob Health Action. (2015) 8:29978. doi: 10.3402/gha.v8.29978

22. White MP, Alcock I, Grellier J, Wheeler BW, Hartig T, Warber SL, et al. Spending at least 120 minutes a week in nature is associated with good health and wellbeing. Sci Rep. (2019) 9:7730. doi: 10.1038/s41598-019-44097-3

23. Frumkin H, Bratman GN, Breslow SJ, Cochran B, Kahn PH Jr, et al. Nature contact and human health: a research agenda. Environ Health Perspect. (2017) 125:075001. doi: 10.1289/EHP1663

24. Alcock I, White MP, Pahl S, Duarte-Davidson R, Fleming LE. Associations between pro-environmental behaviour and neighbourhood nature, nature visit frequency and nature appreciation: evidence from a nationally representative survey in England. Environ Int. (2020) 136:105441. doi: 10.1016/j.envint.2019.105441

25. WHO. Social Determinants of Mental Health. (2017). Available online at: http://www.who.int/social_determinants/en/ (accessed February 4, 2021).

26. Wang J, $\mathrm{Li} \mathrm{S}$, $\mathrm{He}$ B. Chinese physicians' attitudes toward eco-directed sustainable prescribing from the perspective of ecopharmacovigilance: a cross-sectional study. BMJ Open. (2020) 10:e035502. doi: 10.1136/bmjopen-2019-035502

27. Janson C, Henderson R, Löfdahl M, Hedberg M, Sharma R, Wilkinson AJK. Carbon footprint impact of the choice of inhalers for asthma and cOPD. Thorax. (2020) 75:82-4. doi: 10.1136/thoraxjnl-2019-213744

28. Macneill AJ, McGain F, Sherman JD. Planetary health care: a framework for sustainable health systems. Lancet Planetary Health. (2021) 5:e668. doi: 10.1016/S2542-5196(21)00005-X

29. McLean M, Gibbs T, McKimm J. Educating for planetary health and environmentally sustainable health care: responding with urgency. Med Teach. (2020) 42:1082-4. doi: 10.1080/0142159X.2020.1795107

30. Shaw E, Walpole S, McLean M, Alvarez-Nieto C, Barna S, Bazin $\mathrm{K}$, et al. AMEE consensus statement: planetary health and education for sustainable healthcare. Med Teacher. (2021) 43:272-86. doi: 10.1080/0142159X.2020.1860207

31. Mortimer F, Isherwood J, Wilkinson A, Vaux E. Sustainability in quality improvement: redefining value. Future Healthc J. (2018) 5:88-93. doi: 10.7861/futurehosp.5-2-88

32. Mortimer F, Isherwood J, Pearce M, Kenward C, Vaux E. Sustainability in quality improvement: measuring impact. Future Healthc J. (2018) 5:947. doi: 10.7861/futurehosp.5-2-94

33. Connor A, Mortimer F. The green nephrology survey of sustainability in renal units in England, Scotland and wales. J Ren Care. (2010) 36:15360. doi: 10.1111/j.1755-6686.2010.00183.x

34. Thiel CL, Schehlein E, Ravilla T, Ravindran RD, Robin AL, Saeedi OJ, et al. Cataract surgery and environmental sustainability: waste and lifecycle assessment of phacoemulsification at a private healthcare facility. J Cataract Refract Surg. (2017) 43:1391-8. doi: 10.1016/j.jcrs.2017.08.017

35. Centre for Sustainable Healthcare (2021). Available online at: https:// sustainablehealthcare.org.uk/ (accessed February 4, 2021).

36. United Nations Economic Commission for Europe (UNECE). Sustainable Development: The Co-benefits of Climate Change Mitigation. (2016). Available online at: https://unece.org/DAM/Sustainable_Development_No._ 2_Final_Draft_OK_2.pdf (accessed February 4, 2021).

37. WHO. Health and Climate Change Toolkit: Health Co-benefits of Climate Action. (2021). Available online at: https://www.who.int/activities/buildingcapacity-on-climate-change-human-health/toolkit/cobenefits (accessed February 4, 2021).

38. Parker, AV. Learning the language of the land [master's thesis]. Victoria, BC: University of Victoria (2002).

39. UNESCO. Biodiversity and Linguistic Diversity. (2017). Available online at: http://www.unesco.org/new/en/culture/themes/endangered-languages/ biodiversity-and-linguistic-diversity/ (accessed March 31, 2021).

40. Warde F, Papadakos J, Papadakos T, Rodin D, Salhia M, Giuliani M. Plain language communication as a priority competency for medical professionals in a globalized world. Can Med Educ J. (2018) 9:e52-9. doi: $10.36834 / \mathrm{cmej} .36848$
41. Redvers N, Schultz C, Vera Prince M, Cunningham M, Jones R, Blondin B. Indigenous perspectives on education for sustainable healthcare. Med Teach. (2020) 42:1085-90. doi: 10.1080/0142159X.2020.1791320

42. Rogers W. Moral responsibility in medicine: where are the boundaries? Lancet. (2020) 396:373-4. doi: 10.1016/S0140-6736(20)31643-3

43. Lorencatto F, Charani E, Sevdalis N, Tarrant C, Davey P. Driving sustainable change in antimicrobial prescribing practice: how can social and behavioural sciences help? J Antimicrob Chemother. (2018) 73:261324. doi: $10.1093 / \mathrm{jac} / \mathrm{dky} 222$

44. Pongsiri MJ, Gatzweiler FW, Bassi AM, Haines A, Demassieux F. The need for a systems approach to planetary health. Lancet Planet Health. (2017) 1:e257-e9. doi: 10.1016/S2542-5196(17)30116-X

45. Michie S, Van Stralen MM, West R. The behaviour change wheel: a new method for characterising and designing behaviour change interventions. Implementation Sci. (2011) 6:42. doi: 10.1186/1748-5908-6-42

46. Cabana MD, Rand CS, Powe NR, Wu AW, Wilson MH, Abboud PA, et al. Why don't physicians follow clinical practice guidelines? A framework for improvement. JAMA. (1999) 282:1458-65. doi: 10.1001/jama.282. 15.1458

47. Kanene KM. Indigenous practices of environmental sustainability in the tonga community of southern zambia. JAMBA. (2016) 8:331. doi: 10.4102/jamba.v8i1.331

48. Sarmiento I, Zuluaga G, Paredes-Solís S, Chomat AM, Loutfi D, Cockcroft A, et al. Bridging western and indigenous knowledge through intercultural dialogue: lessons from participatory research in mexico. BMJ Global Health. (2020) 5:e002488. doi: 10.1136/bmjgh-2020-002488

49. Morton Ninomiya ME, Atkinson D, Brascoupé S, Firestone M, Robinson N, Reading J, et al. Effective knowledge translation approaches and practices in indigenous health research: a systematic review protocol. Syst Rev. (2017) 6:34. doi: 10.1186/s13643-017-0430-x

50. Redvers N, Blondin BS. Traditional indigenous medicine in north america: a scoping review. PLoS ONE. (2020) 15:e0237531. doi: 10.1371/journal.pone.0237531

51. Redvers N, Marianayagam J, Blondin B. Improving access to indigenous medicine for patients in hospital-based settings: a challenge for health systems in northern Canada. Int J Circumpolar Health. (2019) 78:1589208. doi: 10.1080/22423982.2019.1589208

52. Carrie H, Mackey TK, Laird SN. Integrating traditional indigenous medicine and western biomedicine into health systems: a review of nicaraguan health policies and miskitu health services. Int J Equity Health. (2015) 14:129. doi: 10.1186/s12939-015-0260-1

53. Torri MC, Hollenberg D. Indigenous traditional medicine and intercultural healthcare in bolivia: a case study from the potosi region. J Commun Health Nurs. (2013) 30:216-29. doi: 10.1080/07370016.2013. 838495

54. Gottlieb K. The nuka system of care: improving health through ownership and relationships. Int J Circumpolar Health. (2013) 72:1. doi: 10.3402/ijch.v72i0.21118

55. Tilburt JC, Miller FG. Responding to medical pluralism in practice: a principled ethical approach. J Am Board Fam Med. (2007) 20:48994. doi: 10.3122/jabfm.2007.05.060205

56. Esposito ML, Kahn-John M. How should allopathic physicians respond to Native American patients hesitant about allopathic medicine? AMA J Ethics. (2020) 22:E837-44. doi: 10.1001/amajethics.2020.837

57. Robinson JM, Gellie N, Maccarthy D, Mills JG, O’Donnell K, Redvers N. Traditional ecological knowledge in restoration ecology: a Call to listen deeply, to engage with, and respect indigenous voices. Restor Ecol. (2021) e13381. doi: 10.1111/rec.13381

58. Flicker S, O'Campo P, Monchalin R, Thistle J, Worthington C, Masching R, et al. Research done in "A good way:" the importance of indigenous elder involvement in hIV community-based research. Am J Public Health. (2015) 105:1149-54. doi: 10.2105/AJPH.2014.302522

59. Wabnitz KJ, Gabrysch S, Guinto R, Haines A, Herrmann M, Howard $\mathrm{C}$, et al. A pledge for planetary health to unite health professionals in the anthropocene. Lancet. (2020) 396:1471-3. doi: 10.1016/S0140-6736(20) 32039-0

60. Heke I, Rees D, Swinburn B, Waititi RT, Stewart A. Systems thinking and indigenous systems: native contributions to obesity prevention. AlterN 
Int J Indigenous Peoples. (2018) 15:22-30. doi: 10.1177/11771801188 06383

Conflict of Interest: The author declares that the research was conducted in the absence of any commercial or financial relationships that could be construed as a potential conflict of interest.
Copyright $(2021$ Redvers. This is an open-access article distributed under the terms of the Creative Commons Attribution License (CC BY). The use, distribution or reproduction in other forums is permitted, provided the original author(s) and the copyright owner(s) are credited and that the original publication in this journal is cited, in accordance with accepted academic practice. No use, distribution or reproduction is permitted which does not comply with these terms. 